\title{
Trigeminal neuralgia caused by aneurysm of the posterior cerebral artery: a case description and the analysis of anatomical variety of vascular complex in the rood entry zone of trigeminal nerve
}

\author{
J. Dzierżanowski, P. Słoniewski \\ Department of Neurosurgery, Medical University of Gdansk, Poland
}

[Received 26 September 2013; Accepted 16 October 2013]

\begin{abstract}
Trigeminal neuralgia is still a riddle, especially in the pathophysiology of the tic douloureux, although the problem has been described in many medical publications. The major theory of pain based on the compression of the $V^{\text {th }}$ nerve by tumours or vessels in the rood entry zone (REZ) does not explain the facial pain in patient without neurovascular conflict, with multiple sclerosis or with conflict in places other than REZ. We report a case of the posterior cerebral artery aneurysm, which caused the isolated trigeminal neuralgia in a 48-year-old woman. She was operated on through microvascular decompression and the aneurysm was wrapped. In the second part of this study we review morphological variations of the neurovascular conflict on the basis of anatomical publications. (Folia Morphol 2014; 73, 2: 224-228)
\end{abstract}

Key words: trigeminal neuralgia, intracranial aneurysm, posterior cerebral artery, microvascular decompression, neurovascular conflict

\section{INTRODUCTION}

Paroxysmal face pain in the range of the branches of the trigeminal nerve is a complaint patients report to doctors of different specialisations - from family doctors to dentists, laryngologists, neurologists and lastly to neurosurgeons. The cause of the following complaints may be differential - injury, inflammatory process, hyperplasial process, multiple sclerosis and vascular/neural incompatibility [6]. Trigeminal neuralgia (TGN) occurs with a mean incidence of 8 patients per 100,000 of the population, the peak of falling ill is between the ages of $50-60[6,9]$. There are 2 types of neuralgia in the nomenclature: idiopathic and a secondary one. Although the pathophysiology of all aspects of the tic douloureux has not been fully explained, it seems that it is the result of the compression of trigeminal nerve at its exit from the pons.

We report a case of the posterior cerebral artery aneurysm, which caused isolated TGN. We have not found any similar vascular correlation in the literature. In the second part of this study we review morphological variations of the neurovascular conflict on the basis of anatomical publications.

\section{CASE REPORT}

The patient (48-year-old woman) was admitted to the Neurosurgery Department with diagnosed aneurysm with poor defined neck of the right posterior 


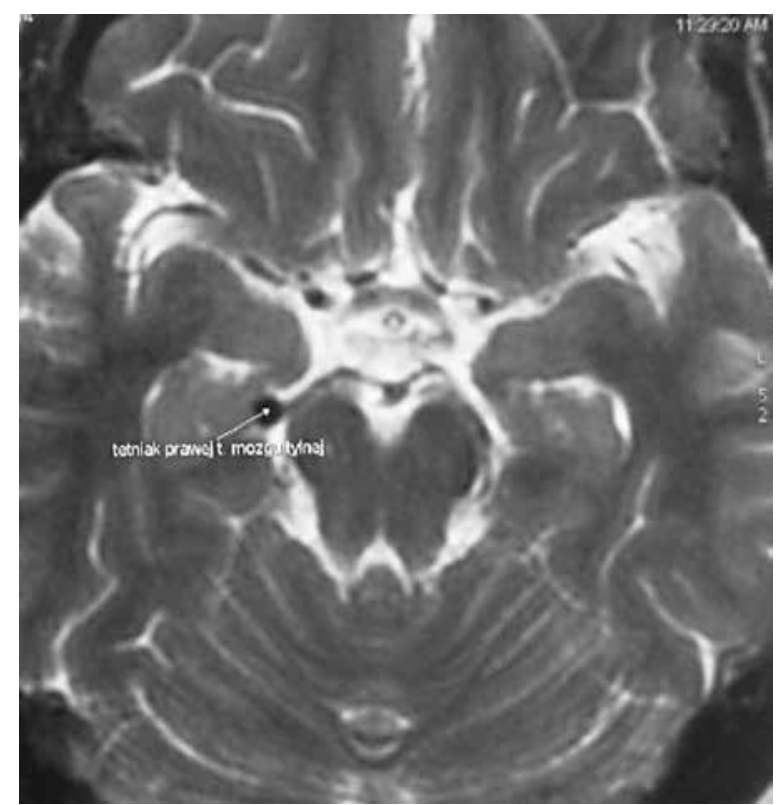

Figure 1. Magnetic resonance scan with visible aneurysm on the posterior cerebral artery; tętniak prawej t. mózgu tylnej — aneurysm of the posterior cerebral artery.

cerebral artery and the symptoms of the neuralgia from the maxillary division (V2). She suffered from the face pain for about 1.5 year and was primary treated typically using carbamazepine with partial respond. The performance of the magnetic resonance (MR) scan (Fig. 1) suggested the suspicion of the aneurysm of posterior cerebral artery and then it was confirmed in the angio-tomocomputer (angio-CT) scans and the cerebral angiography (Fig. 2). Because the patient suffered from additional form of paroxysmal headache (in the last few weeks), what could suggest the prodromal sings of subarachnoid hemorrhage, we have made a decision of the operation-wrapping the aneurysm and the decompression from the area which could potentially cause symptoms of the $\mathrm{V}^{\text {th }}$ neuralgia.

The operation was performed by the modified pterional approach [24] (Fig. 3), for the aneurysm wrapping we used the artificial haemostatic material and to the decompression same pieces of teflon. During the first day after the operation we have observed excessive somnolence in the patient and the control CT showed focal hemorrhage in the frontal right lobe with local oedema. After pharmacological treatment, the patient gained physical improvement and was discharged from hospital without neurological deficits. The follow-up is now

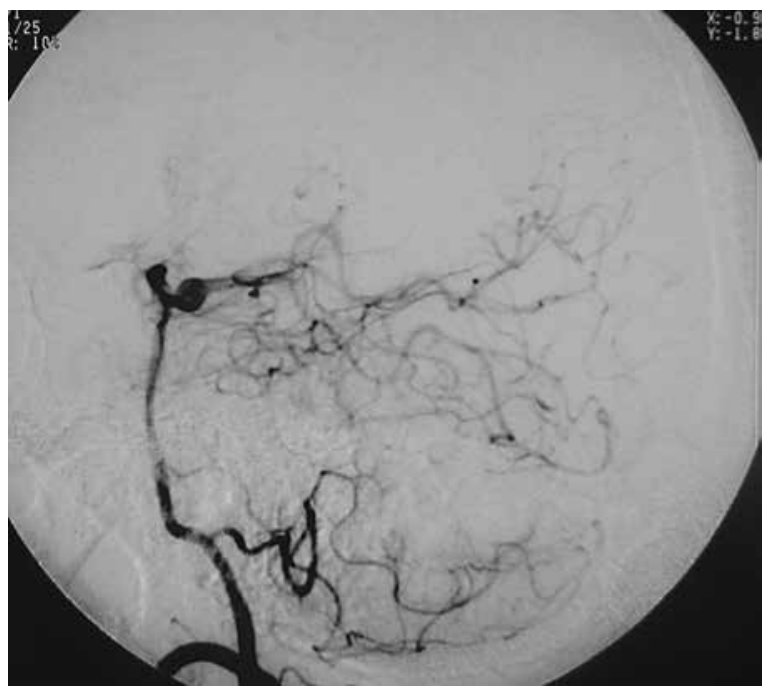

Figure 2. Cerebral angiography showing fusiform aneurysm arising from the direct trunk of the posterior cerebral artery.

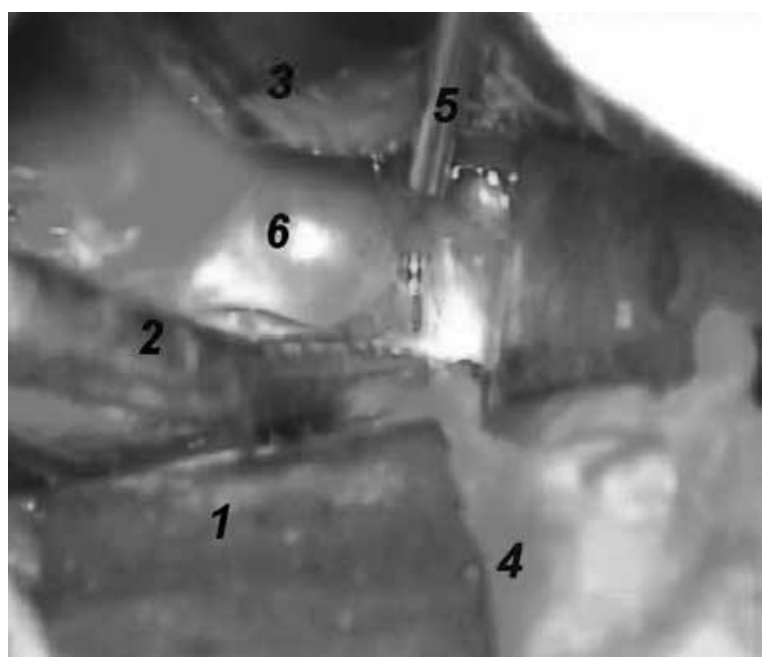

Figure 3. The operating field: 1 - retractor; 2 - suction tube; 3 - temporal lobe; 4 - frontal lobe; 5 - aneurysm on the posterior cerebral artery; 6 - surgical microinstrument.

more than 3 years and the patient is still free of the facial pain.

\section{DISCUSSION}

Some authors have reported TGN caused by the conflict with aneurysms on the anterior inferior cerebellar artery (AICA), posterior communicating artery and basilar artery (BA) $[4,10,13,20,26,27$, 29]. In most publications there was not isolated idiopathic neuralgia, but the effect of compres- 
sion of more intracranial nerves. The most often coexisted facial, oculomotor and abducens palsy $[4,26,27]$.

Sudden headaches in a patient with diagnosed intracranial aneurysm can be a prodromal sing of subarachnoid hemorrhage. Because the patient was not qualified to intravenously procedures, we have decided for the operation.

Trigeminal neuralgia is characterised by a sudden, sharp, brief and recurrent pain, that is usually unilateral and concerns 1 or more divisions of the $V^{\text {th }}$ cranial nerve. Most theories of TGN postulate vascular compression of the nerve in the root entry zone (REZ) or at the central-peripheral myelin transition zone, known as the Obersteiner-Redlich Line $[7,16]$. The REZ is defined as the anatomical junction between the nerve and the brainstem with central myelination. The compression is a cause of nerve demyelination and ephaptic transmission or ectopic impulse generation between adjacent denuded axons. It leads to neuronal hyperactivity caused by deafferentation $[2,6]$. Unfortunately, the compression does not explain the tic douloureux in patients with multiple sclerosis. Similarly, how to explain clinical signs of neuralgia in patients with negative MR examination and negative surgical verification?

From the anatomical study performed by Perker et al. [16] on 100 trigeminal nerves (50 cadavers) follows that the cisternal portion ranged $8-15 \mathrm{~mm}$ (mean $12.3 \mathrm{~mm}$ ), but the central myelin is located only in initial $1 / 4$ part of the nerve. The compression in this place can explain the TGN, nevertheless many authors suggest that the problem of neuralgia may concern all cisternal portion of the $\mathrm{V}^{\text {th }}$ nerve $[15$, $16,21,23]$.

In a large series of 579 patients with TGN operated by microvascular decompression, vascular conflict was detected so often in the transition zone as in the middle third of the nerve $(54.3 \%)$, and at the point of entry into Meckel's cave in $9.8 \%$ [22].

On the other hand, many authors emphasise that they have not found intraoperatively a neurovascular conflict. The percentage is approximately $0-28 \%$, and it depends on the number of microdecompression series $[1,11,17,21,23,25,30]$. It is the cause why they have concluded that vascular compression may be the predominant, but not the sole cause of TGN and the pathophysiology of pain is still unclear $[12,21,23]$.

\section{ANALYSIS OF THE ANATOMICAL VARIATIONS OF NEUROVASCULAR CONFLICT}

Anatomical publications concerning the variation of neurovascular conflict in TGN can be divided on 2 types: studies on cadavers and observations during the surgical procedures.

Clinical studies show that the most common vessel causing trigeminal conflict is the superior cerebellar artery (SCA) $(66-88 \%)[7,11,22]$, less often the AICA (7.5-25\%) [11, 22], vein vessels (5.5$-13 \%)[1,22]$ and intermittently the vertebral artery with the BA $(1.1-3.5 \%)[11,22]$, and the posterior cerebellar artery $(0-1.0 \%)[1,11]$. In the anatomical study based on the examination of 50 cadaver heads, Hardy and Rhoton et al. [8] showed the arterial conflict in $58 \%$ of all specimens, and in $87 \%$ it concerned SCA. Smaller proportion was observed by Haines et al. [7] (based on 40 trigeminal nerves, without the knowledge about the history of facial pain during the life) - it was $35 \%$ and $100 \%$ concerned SCA. The most common configuration was the caudal loop of SCA cross-compressed the trunk of the $V^{\text {th }}$ nerve [7]. Similar results were obtained by Ramesh and Premkumar [18] during the studies of 100 cadavers. From 39 confirmed vascular conflicts, $59 \%$ concerned SCA, 18\% AICA and $13 \%$ the pontine branches of BA. Unfortunately, we do not have the information about the history of TGN in these humans analogously as in the previous publication. In the other anatomical study, Klun and Prestor [12] examined 130 specimens ( 65 heads) and observed 42 examples of contact and 10 instances of compression of the vessels with the REZ of the $\mathrm{V}^{\text {th }}$ nerve. In the analysed group, 30 conflicts were related to arterial vessels $(53.8 \%-\mathrm{SCA}, 25.6 \%-\mathrm{AICA}$, $20.6 \%$ - the pontine branches of $B A), 11$ may have components of the vein, and only 1 anatomical specimen with unequivocal compression by vein vessel was found [12].

It should be mentioned about the casuistic cases of neuralgia caused by the relation with primitive trigeminal artery or the trigeminocerebellar artery. Primitive trigeminal artery is the embryonic form of anastomosis of the intracavernous division of the internal carotid artery with BA, which can be found in arteriography in approximately $0.1-0.7 \%$. Considering its course, it can give symptoms of compression of abducens and trigeminal nerves [3]. Tuccar et al. [28] showed that analogical situation can also apply to 
trigeminocerebellar artery, which is the branch of BA lying between $\mathrm{V}^{\text {th }}$ nerve and the hemisphere of cerebellum.

The conflict with venous vessel is the less frequent reason of neuralgia and it is $14 \%$ according to Dandy [5]. Haines et al. [7] showed similar percentage $(12.5 \%)$ of the patients, and only $7.5 \%$ of the cadavers. In the other observations the percentage was $7.5-16.6 \%[11,18,30]$ and it was the only reason of TGN in patients undergoing surgery. According to Rhoton [19] and Matsushima et al. [14], the most common anatomical variations of venous compression are: the transverse pontine vein, the vein of the middle cerebellar peduncle, the vein of the cerebellopontine fissure, the pontotrigeminal vein and the lateral mesencephalic vein $[14,19]$. Taking into consideration the situation in which the compression of trigeminal nerve is caused by vein and artery, the percentage increases to $20-68 \%[1,14,22]$.

The authors of the above studies suggest some limitations in the explanation of the obtained results from the anatomical examinations on the cadavers, which result from 2 facts. Firstly, vessels at postmortem examination are not filled with blood (they do not pulsate) and it is sometimes hard to distinguish what is "touching" (without distortion) and what is "compressing" in the relation between the nerve and the vessel. The second cause is that vessels can change their position during the preparation (hardening, fulfilling the vessel with synthetic material) $[7,11,17]$.

\section{CONCLUSIONS}

In the available medical literature we have not found analogical case of the isolated maxillar division neuralgia due to the large fusiform posterior cerebral artery aneurysm, without any other neurological signs.

From the presented analysis of the anatomical studies regarding vascular relations to the trigeminal nerve it follows that the problem of neurovascular conflict is complex. Detailed anatomical knowledge of the vascular relation to the $\mathrm{V}^{\text {th }}$ nerve is very helpful in planning the surgical microdecompression.

\section{REFERENCES}

1. Barker FG, Jannetta PJ, Bissonnette DJ, Larkins MV, Jho HD (1996) The long-term outcome of microvascular decompression for trigeminal neuralgia (1185 cases). N Engl J Med, 334: 1077-1083.

2. Calvin W, Loeser J, Howe J (1977) A neurophysiological theory for the pain mechanism of tic douloureux. Pain, 3: 147-154.
3. Clerici A, Merlo P, Rognone F, Noce M, Rognone E, Bono G (2009) Persistent trigeminal artery causing "double" neurovascular conflict. Headache, 49: 472-476.

4. Constans JP, Visot A, Fredy D, Dorland P (1976) Giant aneurysm of the basilar trunk presenting as essential facial neuralgia. Neurochirurgie, 22: 493-502.

5. Dandy WE (1934) Concerning the cause of trigeminal neuralgia. Am J Surg, 24: 447-455.

6. Grant G, Loeser J (2005) Trigeminal neuralgia. In: Rengachary SS, Ellenbogen RG ed. Principles of neurosurgery. Elsevier Limited, Philadelphia, pp. 777-784.

7. Haines S, Jannetta P, Zonun D (1980) Microvaseular relations of the trigeminal nerve An anatomical study with clinical correlation. J Neurosurg, 52: 381-386.

8. Hardy DG, Rhoton AL Jr. (1978) Microsurgical relationships of the superior cerebellar artery and the trigeminal nerve. J Neurosurg, 49:669-678.

9. Huibin Q, Jianxing L, Guangyu H, Dianen F (2009) The treatment of first division idiopathic trigemninal neuralgia with radiofrequency thermocoagulation of the peripherial branches compared to conventional radiofrequency. J Clin Neurosci, 16: 1425-1429.

10. Ildan F, Gocer A, Bagdatoglu H, Uzuneyiipoglu Z, Tuna M, Cetinalp $E$ (1996) Isolated trigeminal neuralgia secondary to distal anterior inferior cerebellar artery aneurysm Neurosurg. Rev, 19: 43-46.

11. Klun B (1992) Microvascular decompression and partial sensory in the treatment of trigeminal neuralgia. Neurosurgery, 30: 49-52.

12. Klun B, Prestor B (1986) Microvascular relations of the trigeminal nerve: an anatomical study. Neurosurgery, 19: 535-539.

13. Leopold NA, Hirsh LF, Ray T (1980) Paroxysmal facial neuralgia secondary to a posterior communicating artery aneurysm. Surg Neurol, 14: 221-223.

14. Matsushima T, Huynh-Le P, Miyazono M (2004) Trigeminal neuralgia caused by venous compression. Neurosurgery, 55: 334-339.

15. McLaughlin MR, Jannetta PJ, Clyde BL, Subach BR, Comey CH, Resnick DK (1999) Microvascular decompression of cranial nerves: Lessons learned after 4400 operations. J Neurosurg, 90: 1-8.

16. Peker S, Kurtkaya O, Uzun I, Pamir N (2006) Microanatomy of the central myelin-peripheraila myelin transition zone of the trigeminal nerve. Neurosurgery, 59: 354-359.

17. Piatt JH, Wilkins RH (1984) Treatment of tic douloureux and hemifacial spasm by posterior fossa exploration: therapeutic implication of various neurovascular relationships. Neurosurgery, 14: 462-471.

18. Ramesh VG, Premkumar G (2009) An anatomical study of the neurovascular relationships entry zone. J Clin Neurosc, 16: 934-936.

19. Rhoton AL Jr. (2000) The cerebellopontine angle and posterior fossa cranial nerves by the retrosigmoid approach. Neurosurgery, 47 (suppl. 3): S93-S129.

20. Rosa A, Mizon JP, Sevestre H (1991) Giant vertebro-basilar aneurysm. Frontal syndrome. Rev Neurol, 147: 827-829.

21. Sindou M, Acevedo G (2001) Microvascular decompression of the trigeminal nerve. Oper Tech Neurosurgery, 4: $110-126$. 
22. Sindau M, Howeidy T, Acevedo G (2002) Anatomical observations during microvascular decompression for idiopathic trigeminal neuralgia (with correlations between topography of pain and site of the neurovascular conflict). Prospective study in series of 579 patients. Acta Neurochir, 144: 1-13.

23. Sindou M, Leston J, Howeidy T, Decullier E, Chapuis $F$ (2006) Micro-vascular decompression for primary Trigeminal Neuralgia (typical or atypical). Long-term effectiveness on pain; prospective study with survival analysis in a consecutive series of 362 patients. Acta Neurochir, 148: 1235-1245.

24. Słoniewski P, Dzierżanowski J, Szmuda T (2008) Modification of the pterional approach to pathologies of the interpeduncular fossa-technical description, morphometry and results of treatment. Neuro Neurochir Pol, 42 (suppl. 2): 160-168.

25. Taarnhoj P (1982) Decompression of the posterior trigeminal root in trigeminal neuralgia, a 30-year follow-up review. J Neurosurg, 57: 14-17.
26. Terao S, Hara K, Yoshida K, Ohira T, Kawase T (2001) A giant internal carotid-posterior communicating artery aneurysm presenting with atypical trigeminal neuralgia and facial nerve palsy in a patient with autosomal dominant polycystic kidney disease: a case report. Surg Neurol, 56: 127-131.

27. Trotter MI, Choksey MS (2000) Facial pain with intracranial aneurysm. J R Soc Med, 93: 479-480.

28. Tuccar E, Sen T, Esmer AF (2009) Anatomy and clinical significance of the trigeminocerebellar artery. J Clin Neurosc, 16: 679-682.

29. Zager EL (1991) Isolated trigeminal sensory loss secondary to a distal anterior inferior cerebellar artery aneurysm: case report. Neurosurgery, 28: 829-832.

30. Zorman G, Wilson CB (1984) Outcome following microvascular decompression or partial sensory rhizotomy in 125 cases of trigeminal neuralgia. Neurology, 34: 1362-1365. 